\title{
WIDERSTAND: EL VALOR DE LA RESISTENCIA POLÍTICA EN IMMANUEL KANT
}

\author{
Patricio Lepe Carrión \\ IESC PENSAR \\ Pontificia Universidad Javeriana - Colombia.
}

\begin{abstract}
Resumen.- Este artículo pretende mostrar una nueva interpretación en torno al concepto de widerstand. Históricamente se ha entendido como una negación por parte del sistema jurídico, en tanto la resistencia consistiría en un acontecimiento de suyo reprochable; pero se ha olvidado que para Kant, la modificación de los pilares del Estado, o la transformación de su entorno socio político, sólo es posible por la vía ética (i.e., por un resistencia 'ilustrada') que, como un puente constituye el paso desde una moralidad personal (Doctrina de la Virtud) a una moralidad política (Doctrina del Derecho), y desde aquí, hacia la construcción de una inalcanzable, aunque esperanzadora paz perpetua.
\end{abstract}

Palabras clave.- Widerstand, Aufklarung, resistencia, ilustración, libertad.

Abstract.- This article aims to show a new interpretation on the concept of Widerstand. Has historically been understood as a denial by the legal system, while the resistance would be an event in itself reprehensible, but has forgotten that for Kant, the modification of the pillars of the State or the transformation of its socio-political environment, is only possible through ethics (ie, a resistance 'enlightened') as a bridge is the shift from a personal morality (Doctrine of Virtue) to a political morality (Doctrine of Right) and from there, towards the construction of a unattainable, but hopeful perpetual peace.

Keywords.- Widerstand, Aufklarung, resistance, enlightenment, freedom.

"iDemos gracias, pues, a la naturaleza por la intolerabilidad, por la vanidad competitiva y envidiosa, por el apetito jamás saciado de posesión y de poder! Sin ellos, todas las excelentes disposiciones naturales de la humanidad dormitarían eternamente sin desarrollarse." (laG, Ak Ausg VIII, 21) ${ }^{1}$

Una condición necesaria para el desarrollo de las facultades morales de los hombres, es el aparentemente descarnado dinamismo de la insociable sociabilidad humana: que el individualismo sea la fuente de sostenimiento del socialismo, es una idea que atraviesa casi toda una tradición política que

\footnotetext{
${ }^{1}$ Todas las obras de Kant, a excepción de la Crítica a la Razón Pura (según la paginación de la $2^{\circ}$ ed. 'B') serán citadas conforme a la edición alemana en formato electrónico del Instituto de investigación de la Comunicación y Fonética de la Universidad de Bonn, que se corresponde con la edición de la Academia (Akademie-Ausgabe, en adelante: Ak Ausg). Las traducciones empleadas en este ensayo pueden ser consultadas en la bibliografía final.
} 
comienza en Kant, y que desemboca abiertamente en la contemporaneidad. Kant, es heredero de la tradición política del contrato social de Rousseau, pero esta dialéctica relación entre individuo y sociedad, y la manera en que el fomento de una conlleva necesariamente a la otra, es una idea muy propia de liberalismo burgués del siglo XVII y XVIII ${ }^{2}$; ya lo dirá Hegel en su Filosofía del Derecho, “...puesto que cada uno adquiere, produce y goza para sí, justamente por eso produce y adquiere para el goce de los demás", idea que encierra un oscuro fondo teleológico de la historia, y que acaba por difuminarse en una actualizada forma de entender y estudiar el mundo político de hoy. Veamos lo que dice Kant al respecto de su insociable sociabilidad humana, y de cómo el carácter heurístico de la misma, posibilita sin pocas dificultades, una interpretación contemporánea de su pensamiento, totalmente aplicable a la realidad sociopolítica de la actualidad.

Así, esta idea, tan aceptada en tiempos de nuestro filósofo, fue haciéndose cada vez más propia con el correr del idealismo alemán, por supuesto, enriquecida con el fulgor de las precedentes corrientes políticas derivadas de la época revolucionaria en Francia y EE.UU.

Como reza la cita mascota de este artículo, Kant, en su opúsculo sobre una Historia Universal desde el punto de vista Cosmopolita, agradecía la intolerancia, la insociabilidad, el desprecio, el egoísmo y el odio del hombre hacia los demás hombres; puesto que su instinto agresivo e impulso de auto aniquilación, constituyen las piezas fundamentales de un proceso, algo mecánico y natural, que conduce inevitablemente hacia un desarrollo económico y moral.

Pensar que el egoísmo conllevaría a un fomento de la economía a grandes escalas, nos conduce necesariamente a preguntarnos: ¿Cómo fundar una ética a partir de lo más innato y precario en el corazón de los hombres? Y si fuera así, si el egoísmo constituyera al hombre en su precaria naturaleza, ¿cómo explicar un desarrollo 'natural', o de un impulso 'inteligente' en la naturaleza que conllevaría a los hombres por vías evolutivas?

¿Podemos entonces decir que el dinamismo de la insociable sociabilidad humana, es el único proceso que se abre como camino posible hacia una liberación del individuo de los grilletes a que ha sido encadenado, -grilletes que, por cierto, son el producto de nuestra propia pereza y cobardía (WA, Ak Ausg VIII, 35) -; y que por tanto, esa misma bajeza de estancamiento y poco amor por el desarrollo propio, sea la fórmula política contra el abuso de poder, contra

\footnotetext{
${ }^{2}$ No en vano Adam Smith, fundó las bases de un liberalismo, indicando que:

"Es cierto que, por lo general, nadie se propone fomentar el interés público, no sabe hasta qué punto lo está fomentando. Al preferir dar apoyo a la industria del país más bien que a la extranjera, se propone únicamente buscar su propia seguridad; y encaminando esa actividad de manera que sus productos puedan ser del mayor valor, busca únicamente su propia ganancia, y en éste, como en otros muchos casos, una mano invisible le lleva a fomentar una finalidad que no entraba en sus propósitos. Buscando su propio interés, fomenta frecuentemente el de la sociedad con mayor eficacia que cuando se lo propone realmente" (La Riqueza de las Naciones" Libro IV, Cap. II. Editorial Aguilar. Madrid, 1956. p.377).
} 
las leyes injustas, o simplemente contra la manipulación mediática ejercida por algunos pequeños grupos de la sociedad?

La respuesta es evidentemente: No. Veamos esto con detención, y mantengámonos al margen de las críticas que pudieran surgir al pensamiento de Kant respecto a conceptos como la Libertad, la Coacción, la Rebeldía y la llustración.

La Ungesellige Geselligkeit, o dinamismo de la insociable sociablidad humana, constituye un proceso natural de evolución, manifestada como una estrategia de la misma Naturaleza en su pretensión de sacar a los hombres de su bestialidad, y encaminarlos hacia una humanización. Esto, no implicaría, por ningún motivo, que una vez apaciguados por este dinamismo, los ciudadanos lleguen a una paz en que se respeten unos a otros, o que se impongan por gracia divina- los ideales de Igualdad y Justicia (ideas que a priori, son el sustento para el funcionamiento de un Estado Civil); es decir, la insociable sociabilidad humana, no es capaz de conducir a una moralización de los hombres, sino tan sólo a una reunión legal de los mismos, fundada en la mera conveniencia: 'hasta un pueblo de demonios...'. Para llegar, desde ese estado en que se encuentra, a una Paz de carácter Perpetuo, se hace necesario otro dinamismo capaz de brindar a los hombres una herramienta no sólo de moralización, sino también, y fundamentalmente, de acción liberadora y transformadora de la injusticia social. Para determinar este proceso, y relacionarlo con su intrínseco carácter emancipador, he tomado un concepto kantiano, algo contemporáneo, y a menudo estandarte de las corrientes ideológicas de la política actual: la Resistencia (widerstand); como el vínculo clave entre este aparataje de ideas y aparente contradicción.

II

“...los hombres se aproximan mucho en su conducta externa a lo que prescribe la idea del derecho, aunque con toda seguridad no es la moralidad la causa de ese comportamiento (como tampoco es causa de la buena constitución del Estado, sino más bien al contrario; de esta última hay que esperar la formación moral de un pueblo)" (ZeF, Ak Ausg, VIII, 366).

La Libertad, concepto altamente descripto en su epistemología ${ }^{3}$, y que entendida en términos prácticos, no es otra cosa que 'obediencia' consciente a

\footnotetext{
${ }^{3}$ Insisto en el carácter 'fundador' de la KRV, respecto a su filosofía política o cosmopolítica, es decir, a su visión filosófica en general (véase nota al pie ut infra). La Libertad, en un sentido cosmológico, ya fue justamente analizada en su KRV, respecto a las antinomias de la razón, y en ella se encuentran las bases epistemológicas del eje central de su filosofía práctica: "El concepto de Libertad es u concepto puro de la razón que, precisamente por ello, es trascendente para la filosofía teórica, es decir, es un concepto tal que no puede ofrecerse para él ningún ejemplo adecuado en cualquier experiencia posible; por tanto, no constituye objeto alguno de un conocimiento teórico, posible para nosotros, y no puede valer en modo alguno como un principio constitutivo de la razón especulativa, sino únicamente como uno regulativo y, sin duda, meramente negativo; pero en el uso práctico de la razón prueba su realidad mediante
} 
la ley coercitiva en un contexto de contrato social ampliamente divulgado y aceptado por el pueblo; es sinónimo de obediencia, mas que ciega, absolutamente iluminadora, y dotada del ejercicio constante de la racionalidad ${ }^{4}$. Kant, en su Rechtslehre, obra maravillosa, llena de pasajes oscuros y concisos, plantea que la Libertad (en términos jurídicos) es el ejercicio de nuestras acciones en tanto no perjudican a nadie, esto es, en la medida en que es ejercida en un contexto sociopolítico determinado por ciertas reglas o normas que regulan el comportamiento externo de los individuos; o más bien, que la libertad es tal, sólo si la obediencia a ese conjunto de leyes externas se hace bajo mi consentimiento. Con esto, vale dejar claro dos puntos: primero, que la libertad sólo puede ser ejercida, sólo y a condición de la existencia de un otro, o más bien, de un conglomerado social; lo que parece obvio, no lo es en la medida en que suele confundirse la libertad con ese estado de anarquía interior en que no existe yugo posible que impida hacer y decir lo que se quiera; pues bien, esa versión adolescente de la libertad queda inmediatamente descartada por nuestro filósofo. Mas bien se trataría, entonces, de la condición de posibilidad de la facultad mencionada; algo así como el agua para que un pez pueda emprender su nado, o la fuerza ejercida por el viento en el vuelo de un $a^{5}{ }^{5}$ : no hay libertad donde no exista la coacción ejercida por la presencia de un otro a quien respetar su mismo derecho a ser libre; nótese que el principio regulador que subyace a esta condición, es el mismo que en la ética regía para la razón práctica: el imperativo de actuar conforme a principios que puedan universalizarse; asimismo, la libertad sólo es posible para mí conjuntamente con otros, o dicho en términos aún más comunes, mi libertad comienza donde termina la de los demás. Y segundo, dejar en claro que la libertad entendida como obediencia, responde nada más que a ese principio tan kantiano, por cierto, de autonomía; somos cada vez más libres cuanto más nos hacemos valer por nuestro propio entendimiento. Éste es el motor de la Aufklarung, la madurez de soltar poco a poco la mano de nuestros tutores, en tanto somos capaces de conducirnos sin la ayuda o temor de prohibiciones y mandatos externos. Bajo este postulado, se encuentra oculta la idea que, a mayor uso de nuestra razón, tanto en el diálogo como en el juicio reflexivo, menos útil nos

principios prácticos que demuestran, como leyes, una causalidad de la razón pura para determinar el arbitrio con independencia de todos los condicionamientos empíricos (de lo sensible en general), y que demuestran en nosotros una voluntad pura, en la que tienen su origen los conceptos y leyes morales". (RL, Ak Ausg VI, 221).

De hecho, en su KPV, dirá más tarde que: "El concepto de libertad, en la medida en que su realidad pueda demostrarse mediante una ley apodíctica de la razón práctica, constituye la coronación de todo el edificio de un sistema de la razón pura, aun de la especulativa, $y$ todos los demás conceptos (Dios y la inmortalidad) que en ésta carecen de apoyo como meras ideas, se enlazan con este concepto, y con él y gracias a él adquieren existencia y realidad objetiva, es decir, que su posibilidad se demuestra por el hecho de que la libertad es real, pues esta idea se revela mediante la ley moral" (KPV, Ak Ausg V, 3-4).

\footnotetext{
4 "la libertad jamás puede consistir en que el sujeto racional pueda elegir también en contra de su razón (legisladora)" (RL, Ak Ausg VI, 226).

${ }^{5}$ La analogía hace referencia al ejemplo kantiano: "La ligera paloma, al surcar en libre vuelo el aire cuya resistencia siente, podría persuadirse de que en un espacio vacío de aire le podría ir aún mucho mejor" (KRV, B 8-9).
} 
resulta la ley para el cumplimiento de mi deber como sujeto en sentido jurídico y social. Esto, quiere decir que, todo montaje legislativo, y por tanto, coercitivo ${ }^{6}$, constituye un paso significativo (y jamás entorpecedor) para el crecimiento o madurez de los pueblos. En esto, ve Kant la misma relación que observa en la ética respecto al imperativo cuando distingue entre un medio y un fin en sí mismo; en aquel, decía que nuestra acción, para que fuera moral, debía despojarse de todo tipo de búsqueda empírica (felicidad), puesto que al hacerlo, la motivación final acabaría por convertir nuestra acción en un medio para su consecución, en cambio, una acción motivada simplemente por el deber al cumplimiento de la ley moral (sin más), haría de nuestra acción un fin en sí misma, así al menos lo expresa Kant cuando dice que la naturaleza racional existe como fin en sí misma; o como un imperativo práctico que reza: "obra de tal modo que te relaciones con la humanidad, tanto en tu persona como en la de cualquier otro, siempre como un fin, y nunca sólo como un medio" (GMS, Ak Ausg IV, 429). Lo que quiero plantear con esto es que, al igual que el imperativo, Kant prefiere en su concepción socio política, determinar cuál es el fin y cuál el medio para su consecución; de modo que la distinción entre un aparato legal (el Estado de Derecho), de otro moral (Estado Civil), es justamente que una es el medio necesario para llegar a la otra.

Recuerdo en este sentido lo que Kant plantea respecto a la religión en su Die Religion innerhalb der Grenzen der blossen Vernunft (RGV) de 1793 y posteriormente en la obra Der Streit der Fakultäten (SF) de 1798, en que distingue bajo la misma óptica, entre una religión dogmática y otra racional, una como medio y otra como fin $^{7}$. La primera se trataría de un conjunto de prácticas culturales, folclóricas, o costumbristas (danzas, cantos, rezos, etc.); mientras que la segunda, sería el sustrato de la primera, una moral racional en que el sujeto ya no necesite de los temores divinos o infernales para que sea capaz de cumplir con los preceptos dictados por su razón. De la primera, valga decir que, aunque el fanatismo condicione sus acciones bajo una determinada búsqueda empírica, sin darse cuenta, por medio de la fe, o cumpliendo el dogma dictado por su 'dios', ya está de algún modo contribuyendo, quizá inconscientemente, al desarrollo de una sociedad en vías a la democracia. No es extraño entonces, pensar que Kant distinga bajo el mismo modelo su filosofía política ${ }^{8}$. Una persona que cumpla sólo con el aspecto legal exigido por

\footnotetext{
6 “....al derecho está unida a la vez la facultad de coaccionar a quien lo viola, según el principio de contradicción" (RL, Ak Ausg VI, 231)

${ }^{7}$ Pido al lector las disculpas del caso por la auto referencia, pero en un artículo publicado el 2008, plateo la posibilidad de que esta distinción de Kant entre una religión dogmática y racional haya sido motivada realmente por Fichte en una carta personal enviada a él, respecto a la censura de su obra "Ensayo de una crítica a toda revelación" ("Religión natural y religión revelada: un indicio de Fichte en Kant". A PARTE REI. N056, Marzo 2008).
}

\footnotetext{
${ }^{8}$ Más bien debiera decir "cosmopolítica"; ut supra, por filosofía política entenderemos, y en un sentido muy general, la visión conjunta y sistemática de su teoría del derecho y del Estado, filosofía de la historia, ética y antropología, etc., todas, encaminadas al bien del género humano en su totalidad, en tanto 'Weltmann', o más bien, como 'Weltbürger'. Retomo la brillante distinción que hace Juan José Botero en su ensayo "La filosofía política de Kant", en que establece cuatro niveles de acción y reflexión política: a) preferencias o inclinaciones políticas; b) ideas políticas; c) teorías o doctrinas políticas; y d) filosofía política; argumentando que en
} 
la sociedad en la que está inserto (no en un sentido minimalista, sino, de consenso), ya está del mismo modo, aunque inconscientemente, cumpliendo con los preceptos básicos que contribuirían al desarrollo de una sociedad democrática $^{9}$. Si bien, no es lo esperado, sí podemos concluir de ello que, la legalidad es un medio para la consecución de una paz perpetua; pero como ya lo decíamos más arriba, y desarrollado de una manera excepcional por Enrique Ureña, así como el motor de la legalidad lo constituía indudablemente el dinamismo de la insociable sociabilidad humana, el motor que impulsaría a la sociedad hacia una paz perpetua, o hacia un Estado Civil, debía ser un dinamismo diferente, que requería más que el simple impulso casi instintivo de amor/odio, construcción/autodestrucción; requería más bien de un proceso estrictamente racional: la Ilustración ${ }^{10}$.

Así, el largo y penoso camino que conlleva el aprendizaje de las normas de conducta, el sentimiento de represión causado por el sistema jurídico de una sociedad determinada, es como bien lo plantea Luis Eduardo Hoyos en "La actualidad de Kant"11 como un proceso absolutamente necesario; o cuando compara este proceso de aprendizaje al de aprender un idioma: una vez pasado el período lánguido y tedioso, de soledad y frustración, se abrirán nuevas puertas de libertad y dominio, en que ya no dependerá de alguien que interprete por él una lectura, o que traduzca lo que 'se quiere decir' con determinado gesto o palabra; él mismo tomará las riendas de su vida, y de manera autónoma logrará tomar decisiones sin depender de nadie más que su astucia y perspicacia ${ }^{12}$.

Kant se hayan textos de los tres últimos niveles, puesto que de sus preferencias no podemos decir mucho. Al último nivel, que en este artículo asimilo como 'cosmopolítico', es al que apunta toda la filosofía kantiana. En palabras de Botero, este último nivel significaría: "Lo que se discute aquí tiene que ver con la vida política en cuanto dimensión de la existencia humana y debe, a la vez, encajar consistentemente en y desprenderse lógicamente de una visión o concepción filosófica general referida a otros ámbitos y dimensiones de la existencia" (véase en: Hoyos, L.E.; Patarroyo, C.; Serrano, G. Kant: entre sensibilidad y razón. Universidad Nacional de Colombia. Bogotá, 2006).

9 “... una sociedad sí puede exigir a los ciudadanos que vivan según unas orientaciones de justicia. Por eso es posible de facto el pluralismo moral: porque ya hay unos mínimos de justicia (libertad, igualdad, diálogo, respeto) compartidos por las morales de máximos. Y esta moral cívica orienta la legalidad, que no sólo se exige, sino que se impone, si es necesario, mediante sanción." (Cortina, Adela. Ética Mínima, introducción a la filosofía práctica. Tecnos. Madrid, 2000. P.83).

${ }^{10}$ Cf. Ureña, Enrique. Kant, predecesor de Marx y de Freud. Tecnos, Madrid, 1979. pp. 51-52.

${ }^{11}$ Hoyos, Luis Eduardo (Ed.). Estudios de Filosofía Política. Universidad Nacional de Colombia. Bogotá, 2004. Pp. 199-220.

${ }^{12}$ Es notable el ejemplo que pone Hoyos de la película Moonligthing del director Jerzy Skolimowski. Donde un grupo de albañiles polacos viajan a Inglaterra, y sólo uno de ellos sabe inglés; naturalmente éste se convierte en el líder del grupo, interpretando y tomando decisiones por ellos, al punto que consigue abusar de su condición, sometiendo a sus compañeros a su plena voluntad. 
III

"Vivimos en un tiempo de disciplina, cultura y civilidad; pero aún no, en el de la moralización. Se puede decir, en el estado presente del hombre, que la felicidad de los Estados crece al mismo tiempo que la desdicha de las gentes. Y es todavía un problema a resolver, si no seríamos más felices en el estado bárbaro, en que no existe la cultura actual, que en nuestro estado presente. Pues ¿cómo se puede hacer felices a los hombres, si no se les hace morales y prudentes? La cantidad del mal no disminuirá, si no se hace así." (Päd, Ak Ausg IX, 451)

¿Qué es la resistencia? ¿A qué resistir? ¿Cómo entenderla hoy desde una perspectiva kantiana, si el filósofo rechazaba abiertamente todo tipo de emancipación violenta?

Kant, ha sido ampliamente criticado por su aparente actitud temeraria y contradictoria, al considerar los actos de rebeldía contra la soberanía como el mayor de los delitos de un Estado. Esto, porque consideraría que estar en contra de la soberanía de un país, sería como estarlo en contra de sí mismo, en tanto la constitución política de un Estado cualquiera es siempre la expresión soberana de la voluntad del pueblo; esto es, que para Kant, un contrato originario y soberano, nos hace a nosotros mismos 'colegisladores' en tanto partícipes de la autoridad. Evidentemente nos encontramos frente al ya famoso 'como si' (als ob) de la filosofía kantiana ${ }^{13}$ : el legislador debe dictar leyes 'como si éstas pudieran haber emanado de la voluntad unida de todo el pueblo'; otorgando legitimidad en la medida que el pueblo las aprueba ${ }^{14}$. Y viceversa, el pueblo actúa 'como si el legislador representara fehacientemente su voluntad'15. En este aspecto, Francia y EE.UU. si bien representan para Kant el logro político más avanzado de su época, se habrían equivocado al derrocar violentamente a sus legisladores (Cf. nota al pie sobre el regicidio RL, Ak Ausg VI, 320), y jamás podrán obtener una constitución más justa que la que han derogado; y en caso que obtuviesen por medio de una revolución una constitución diferente, en ningún caso, podrían los ciudadanos estimar la

\footnotetext{
${ }^{13}$ Se trata del cuarto imperativo kantiano, según Philonenko (historiador de la filosofía, de nacionalidad francesa, especialista en filosofía alemana, en Fichte y Kant), citado por Francisco Contreras, en nota al pie n 245 , en: Contreras Peláez, Op. Cit. p. 84.

${ }^{14}$ Cf. Contreras Peláez, Francisco J.. El tribunal de la Razón; el pensamiento jurídico de Kant. Ed. Mad-Eduforma. Sevilla, 2005. Pp.83-84.

${ }^{15}$ Vale mencionar que aquí no hacemos referencia al 'querer' particular de cada ciudadano, eso sería tan ambiguo y contradictorio que se haría imposible la búsqueda de principios comunes en una sociedad. Kant, rompe con el eudemonismo en la moral, al declarar la búsqueda y respeto al 'deber' como motor de nuestras acciones; pues bien, esa búsqueda común de todos los ciudadanos 'debe' ser la conquista de un orden social y político fundado en la moralidad, una vida comunitaria sostenible en el tiempo. Esto no quita obviamente, que cada cual obtenga y se exprese en un estilo de vida a su manera, aunque, por un lado sin coartar la libertad que sus pares tienen, y que 'reconozca su irrenunciable y necesaria participación social' (véase, Hoyos. Op. Cit. p. 203-204).
} 
posibilidad de 'volver' a la legislación que han sepultado. De este modo, la sublevación al poder legislativo es categóricamente reprochable:

“...toda oposición al poder legislativo supremo, toda sublevación que permita traducir en actos el descontento de los súbditos, todo levantamiento que estalle en rebelión es, en una comunidad, el crimen más grave y condenable, pues arruina el fundamento mismo de la comunidad." (TP, Ak Ausg VIII, 299)

La ley es inviolable, y comete un crimen igualmente quien la cuestione -dice Kant-; es por ello que existe ese viejo adagio "toda autoridad viene de Dios" (RL, Ak Ausg VI, 319). Con esto Kant, más que mostrar un servilismo vergonzoso, como han manifestado algunos, intenta demostrar la coherencia con su obra crítica en general; ya que, como el mismo aclara (frase a la cual se le ha prestado escasa atención), diciendo que aquella sentencia autoritaria debe interpretarse solamente como si fuera una "Idea como principio de la razón práctica", esto es, como un modelo "heurístico" que posibilite una planificación racionalizada de comprender el devenir humano, con un carácter de suyo hipotético y jamás dogmático. La Idea reguladora de Kant, es una metodología para comprender los procesos históricos y culturales, se asemeja al concepto de aufheben en Hegel, en tanto Idea que garantiza una superación de lo establecido ${ }^{16}$. Es preciso aclarar este punto aquí, puesto que es de lo más confuso. Aún hay autores que arguyen la débil necesidad que tuvo Kant en recurrir al poder divino. Pues bien, no hay en Kant semejante "poder" sobrenatural ni en su ética ni en su política, esto es, ni en el fuero interno o el externo. Lo que hay, es una aufheben, una Idea que regula de manera exclusivamente "provisoria" el quehacer humano, o como muy bien lo expresa Joaquín Barceló:

"...los esfuerzos políticos humanos se revelan como dotados de sentido únicamente si se presupone la realidad trascendental práctica (y no empírica) de las ideas reguladoras que los informan; de otro modo, dichos esfuerzos no pasarían de ser mera expresión de arbitrariedad, capricho e insensatez"17

El mismo Kant, cuando quiere justificar la inviolabilidad de la Ley en su Rechtslehre, elabora dos textos que, a mi juicio son de mucha relevancia para aclarar este tema; dos textos que, aunque aparecen en la misma obra, se sitúan en diferentes circunstancias, aunque ambos referentes a la "garantía" de actuar conforme al deber; uno en sentido 'ético', y el otro en sentido 'político', y ambos mediados por el Derecho; es decir, un aspecto individual y otro social. A continuación una cita sinóptica:

\footnotetext{
${ }^{16}$ De hecho el mismo concepto de Aufheben, contiene en su significación la doble idea de conservación y la de poner fin.

17 Barceló, Joaquín (comp.). Selección de escritos políticos de Immanuel Kant (Introducción). Estudios Públicos, Número 34. 1989. p. 5.
} 
"Una ley (práctico-moral) es una proposición que contiene un imperativo (mandato) categórico. El que manda (imperans) a través de una ley, es el legislador (legislator). Es autor (autor) de la obligatoriedad de la ley; pero no es siempre autor de la ley. En el caso de que lo fuera, la ley sería positiva (contingente) $y$ arbitraria. La ley que nos obliga a priori e incondicionalmente mediante nuestra propia razón, puede también expresarse como procediendo de la voluntad de un legislador supremo, es decir, de un legislador que sólo tiene derechos y ningún deber (por tanto una voluntad divina); pero esto sólo supone la idea de un ser moral, cuya voluntad es la ley para todos, sin pensarlo, sin embargo, como autor de la ley" (RL, Ak Ausg VI, 227).
"Una ley que es tan sagrada (inviolable) que, considerada con un propósito práctico, es ya un crimen sólo ponerla en duda, por tanto, suspender momentáneamente su efecto, se representa como si no tuviese que proceder de hombres, sino de algún legislador supremo e intachable, y éste es el significado de la proposición: 'toda autoridad viene de Dios', que no enuncia un fundamento histórico de la constitución civil, sino una idea como principio práctico de la razón: el deber de obedecer al poder legislativo actualmente existente, sea cual fuere su origen" (RL, Ak Ausg VI, 319).

Aquí, la inviolabilidad de la Ley, es garantizada por el respeto a una Idea reguladora que otorgue sentido al quehacer humano. La diferenciación de dos momentos, tanto en la ética como en la política, es clave en este asunto: uno de inmadurez, como sucede en la religión, se trata de un momento de creencias irracionales que superan el entendimiento, donde no importa su procedencia divina -incuestionable por cierto-, pero que a la vez son creencias necesarias para cumplir con ciertos mínimos morales (cumpliendo con los preceptos y mandatos divinos se está a la vez, y sin darse cuenta, cumpliendo con las exigencias mínimas de la sociedad); y por otro lado: la Madurez del individuo o de los ciudadanos, en que la Ley es el resultado lógico de la voluntad popular, y por lo mismo toma partido más intensamente en las actividades sociopolíticas, entendiendo que ir contra la Ley es violar la determinación racional de cada ciudadano. En esto Kant es muy claro, sin perjuicio que una sociedad inmadura reciba por imposición y necesariamente, una legislación despótica ${ }^{18}$, pero con una clara finalidad republicana. Un rasgo paternalista o divino, aunque estrictamente propedéutico, que tiene por objeto la ilustración de sus ciudadanos. Es así como Dios, en tanto origen de la autoridad, no es más que la abstracta categoría aplicable a la urgente necesidad de comprender la relación jurídica del hombre con un ser, o del pueblo con un poder supremo, del cual se dice no tiene más que derechos sin ningún deber.

\footnotetext{
${ }^{18}$ Que nunca prive al ciudadano de su derecho a expresarse.
} 
Por otro lado, para Kant, el Estado no puede jamás ser dictatorial (kein diktatorisches), y no puede coartar la libertad de sus ciudadanos en tanto 'expresión'; si bien el derecho, veíamos es coercitivo, jamás imposibilita la libre comunicación entre unos y otros, o entre el Estado y sus ciudadanos, porque el Estado sordo a las demandas del pueblo, es el reflejo de una irracionalidad propia de la tiranía; y como ningún ciudadano puede querer para sí el horror o la muerte, no puede actuar contra el Estado, cuando éste representa la propia voluntad.

La resistencia (Widerstand), no puede ser activa, o violenta; puesto que contradice aquel principio mismo que la razón, en tanto voluntad popular, ha generado. Sólo es posible -dice Kant-, 'una resistencia negativa del pueblo en parlamento ${ }^{19}$; esto es, $-\mathrm{y}$ sigue-, no consentir siempre en todas las demandas que el gobierno hace en nombre del Estado. Esto es fundamental para entender la nueva interpretación que se propone respecto a la Widerstand, que no es otra cosa que una creación de pequeñas ágoras sociales o espacios de intersubjetivación entre los ciudadanos; lugares que posibilitan la existencia de la polis (Auf dieser Freiheit beruht sogar die Existenz der Vernunft). Kant lo expresa claramente cuando dice que: "Sin embargo, para esa ilustración sólo se exige libertad y, por cierto, la más inofensiva de todas las que llevan tal nombre, a saber, la libertad de hacer un uso público de la propia razón, en cualquier dominio" (WA, Ak Ausg VIII, 36).

No hay que olvidar, además, que el 'uso público de la razón', es el criterio epistemológico que Kant utiliza en su KRV para la determinación de una verdad de carácter social ("consentientia uni tertio, consentiunt inter se"), o de una Verdad que se fundamenta no sólo en la concordancia con el objeto (adaequatio rei et intellectus), sino, en la concordancia entre los distintos juicios de cada entendimiento; o dicho de otra modo, la diferencia entre la persuasión como autoreferencia, y la convicción como acuerdo común, es justamente la posibilidad de comunicar su validez a todo ser racional (Cf. KRV, B 848):

“... el fundamento de la concordancia de todos los juicios, a pesar de la diferencia de los sujetos entre sí, descansará en el fundamento común, a saber, en el objeto, con el cual, por eso, todos concordarán y con ello demostrarán la verdad del juicio" (KRV, B 848-849).

De ahí se sigue y comprende el pactum subjectionis civilis, en tanto la obediencia dejaría de ser ciega en la medida en que nadie ni nada prohíbe al ciudadano su facultad de comunicar abiertamente lo que piensa; y el Estado, por otro lado, genera canales en que las críticas puedan ser escuchadas y analizadas en vista a posibles modificaciones legislativas que vayan en provecho de una mejor sociedad.

Nótese lo fundamental de este punto, quizá sea un antecedente obligatorio al artículo 19 de la Declaración de los Derechos Humanos:

\footnotetext{
${ }^{19}$ Los parlamentarios son para Kant, los guardianes de la libertad y los derechos.
} 
"Todo individuo tiene derecho a la libertad de opinión y de expresión; este derecho incluye el de no ser molestado a causa de sus opiniones, el de investigar y el de recibir informaciones y opiniones, y el de difundirlas, sin limitación de fronteras, por cualquier medio de expresión"

Esto es, no se trata simplemente de una "libertad de plumas" en un sentido tan elemental como el "dejar a los ciudadanos escribir", como la interpretación que hacen algunos respetados autores ${ }^{20}$. Sino, más bien, estamos frente a un aspecto clave en la interpretación de la Widerstand como vía posible de una "salida" de la injusticia, abuso y manipulación del poder ejecutivo. ${ }^{21}$

Me parece muy interesante, además, lo que señala la "Convención Americana sobre Derechos Humanos" (CADH), que entra en vigencia en 1978, y que constituye uno de los sistemas protectores a la legitimidad de los DD.HH. en los pueblos americanos. Esta señala, explicando el artículo 19 de la Declaración Fundamental que, la libertad de pensamiento y expresión no debe reducirse a un solo medio, sino que, puede ser tanto oral, impresa, artística o 'cualquier otro medio a su elección o gusto'; y agrega:

"No se puede restringir el derecho de expresión por vías o medios indirectos, tales como el abuso de controles oficiales o particulares de papel para periódicos, de frecuencias radioeléctricas, o de enseres y aparatos usados en la difusión de información o por cualesquiera otros medios encaminados a impedir la comunicación y la circulación de ideas y opiniones". ${ }^{22}$

Toda reforma, entonces, sólo es posible por el soberano, no por el pueblo; éste último no puede tener derechos por sobre el Estado, sino sólo entre sus iguales $^{23}$; al Estado no le debe más que deberes y obligaciones: todo ciudadano debe querer la construcción de una paz permanente, y está obligado a respetar el sistema jurídico que protege la libertad de sus congéneres. La oposición que pueda surgir entre ambas personas morales (el Estado y el Pueblo), es un aspecto central de la gobernabilidad, y por supuesto de la

\footnotetext{
${ }^{20}$ V.g.: Velasco Gómez, Ambrosio. La concepción republicana de kant. Episteme, jun. 2005, vol.25, no.2, p.109-122.

${ }^{21}$ Resaltar la palabra 'ejecutivo'; Kant en una parte de RL, deja abierta la posibilidad de una Widerstand activa, si y sólo si, se efectúa por sobre el poder ejecutivo, pero jamás al legislativo. Un pasaje muy oscuro que denota una idea sin desarrollar mayormente; hablando de una reforma a la constitución política del Estado, dice que sólo puede darse por medio del soberano y no por el pueblo, y de haber alguna, no puede ésta hacerse por una revolución; y agrega: "Si, sin embargo, tuviese esta lugar (la revolución), no puede alcanzar más que al poder ejecutivo, no al legislativo". (RL, Ak Ausg VI, 322; el paréntesis es mío).
}

${ }^{22}$ Art. 13, en Convención Americana sobre Derechos Humanos suscrita en la Conferencia Especializada Interamericana sobre Derechos Humanos. San José, Costa Rica 7 al 22 de noviembre de 1969. En http://www.oas.org/juridico/spanish/tratados/b-32.html.

23 “...un gobierno donde cada uno se posee á sí mismo, y no depende de la absoluta voluntad de otro, sea este otro su igualó su superior, á su lado, o sobre él." (RL, Ak Ausg VI, 317) 
filosofía política kantiana, puesto que, sin ella, el pueblo no demuestra más que su depravación, y el Estado un despotismo sin igual ${ }^{24}$.

Hay un texto magnífico al respecto en la KRV, de cómo la Razón, o más bien, el Estado, se apropia de las demandas ciudadanas, y de cómo la libertad al interior de un sistema jurídico posibilita ese grado de madurez en que los sujetos generan la existencia de una república en la medida en que son capaces de mantener el respeto mutuo entre cada uno de los miembros de la comunidad:

"La razón, en todas sus empresas, debe someterse a la crítica, y no puede menoscabar la libertad de ésta con ninguna prohibición, sin perjudicarse a sí misma y sin atraer sobre sí una sospecha que le es desfavorable. No existe nada tan importante, en lo que toca al provecho, nada tan sagrado, que pueda sustraerse a esta inspección que controla y que examina, y que no conoce acepción de personas. En esa libertad se basa incluso la existencia de la razón, que no tiene autoridad dictatorial (kein diktatorisches), sino que la sentencia de ella es siempre sólo el consenso de ciudadanos libres, cada uno de los cuales debe poder expresar sin reservas sus escrúpulos e incluso su veto" (KRV. B 766-767).

El sometimiento del Estado a la crítica, es el mismo de la Razón respecto al uso polémico de la misma. El Estado está obligado, no por un juez externo a él$^{25}$, pues en sí se encuentra el criterio de autoexaminación, sino más bien, por respeto al único imperativo fundador del contrato que liga a éste con los ciudadanos: "Lo que un pueblo no puede decidir acerca de sí mismo, el legislador tampoco puede decidirlo acerca del pueblo." (TP, Ak Ausg VIII, 304).

IV

“...admitir que el soberano no puede incluso equivocarse o ignorar alguna cosa, sería representarlo como un ser agraciado con inspiraciones divinas y superior a la humanidad." (TP, Ak Ausg VIII, 304)

Discrepo con Francisco Contreras Peláez, quien cree encontrar aquí, en la inviolabilidad de la Ley, el talón de Aquiles del liberalismo kantiano, en que supondría una transformación de la sociedad impulsada siempre "desde arriba", es decir, en la confianza que Kant tiene sobre el monarca, como único guardián y orientador, un monarca 'ilustrado y benevolente', guiador de los pasos de la humanidad hacia una paz perpetua; Error que le costaría a Kant según Contreras P.-, no sólo el epíteto de conservador y cómplice del antiguo régimen, sino también, un rasgo arcaizante de una filosofía dirigida a las masas ilustradas y no al pueblo ignorante. Dice además, que el único recurso que le queda al pueblo, interpretando a Kant y siguiendo a Habermas, es la

\footnotetext{
${ }^{24}$ Cf. RL, Ak Ausg VI, 322.

25 “QQuién, pues, en la contienda debería ser juez entre el pueblo y el soberano?” (RL, Ak Ausg VI, 320).
} 
Offenlichkeit como una especie de 'cuarto poder' frente al imponente poder del soberano ${ }^{26}$.

Evidentemente, esta lectura no puede tener fundamento en su totalidad.

Primeramente, cabe suponer desde una ligera lectura de los textos kantianos que, todo proceso de ilustración nace primeramente en el individuo; y si Kant no está de acuerdo con la resistencia activa, es justamente porque no responde a principios que la misma razón (el Estado, en tanto voluntad general del pueblo) se ha determinado a sí misma. Kant reconoce y legitima una resistencia negativa del pueblo en parlamento; en último término, siempre resistir es llustrarse. De ello resulta que el uso de nuestro propio entendimiento, viene dado por el esfuerzo y superación de nuestra pereza y cobardía, o por el penoso esfuerzo, cuesta arriba, de adjudicarse el valor necesario para autodeterminarse un destino, un modo y estilo de vida. Pero, si hablamos de liberación del individuo, necesariamente debemos hablar también de la fuerza antagónica que impide el uso adecuado del entendimiento, de las sombras que rodean y oscurecen la libertad de las personas; y esa sombra no sólo es, como ya indicábamos, fomentada por nuestra pereza y cobardía, sino, por quienes se benefician de mantenernos en aquel precario estadio. Pero, ¿quién podría gozar o beneficiarse con la ignorancia, el temor, y el silencio ajeno? Es una pregunta que no podremos ahondar en este breve artículo, aunque valga decir, que se trata justamente del soberano déspota a quien no le importa el cuarto imperativo mencionado antes, y gobierna de acuerdo a sus propios intereses.

Kant no escribe a los déspotas; al contrario, hace un llamamiento a los marginados a despertar del letargo causado por el uso ilegítimo del poder. Si no fuera así, la ignorancia sería la bandera que permitiría a los poderosos reinar de una manera descabellada, pero el Sapere Aude de la ilustración se convierte en el sello de su filosofía. No ilustrarse significa para la sociedad el peor de los daños, pero jamás un beneficio:

"Una persona puede postergar su ilustración en lo que le concierne saber sólo para sí misma y únicamente por algún tiempo; pero descuidarla definitivamente para sí o aun para la posteridad equivale a vulnerar y pisotear los derechos sagrados de la humanidad" (WA, Ak Ausg VIII, 39).

Por otro lado, la Offenlichtkeit, es el resultado natural de un ejercicio libre de la razón, pero es imposible que sea el instrumento de contraataque de las masas dominadas e inconscientes, en tanto no se liberen del yugo opresor, esto es, mientras no sean mentes ilustradas; la contradicción en este punto del texto de Francisco Contreras es evidente. Cuando Kant, exige una razón socializadora, ya lo decíamos, no busca encontrar una mera liberación de la 'pluma'; tampoco se trata solamente de institucionalizar o delimitar lugares (en su sentido topológico) de carácter público, de sistemas y roles específicos, sino también, se busca la liberación de comunicación de contenidos y tomas de posturas, que posibilite al ciudadano común alcanzar verdades socioculturales con denotación ética que a la vez le permitan un juicio crítico capaz de transformar su vida, y junto a ello, elaborar una mirada diferente ante la presencia del

${ }^{26}$ Cf. Contreras Pelàez. Op. Cit. Pp. 91-92. 
poder, que le exijan conductas determinadas para modificar su entorno social ${ }^{27}$. La Offentlichkeit, en Kant, es el flujo mismo de una sociedad pluralista, una red donde lo múltiple es una lógica consecuencia de lo particular; pero reitero, para Kant, el camino hacia una Sociedad Civil o hacia una República Nouménica, sólo puede darse por la real e interna transformación de los ciudadanos, he ahí la oscura relación entre especie e individuo, o entre ética y política, o más iluminador aún: entre la Widerstand y la Aufkälung.

\section{Bibliografía}

\section{Obras de Kant:}

Das Bonner Kant-Korpus. Akademieausgabe von Immanuel Kants. http://virt052.zim.uni-duisburg-essen.de/Kant/

\section{Traducciones empleadas}

Kant, Immanuel. Idea para una historia universal en clave cosmopolita, y otros escritos sobre Filosofía de la Historia. Introducción y traducción de Concha Roldán Panadero y Roberto Rodríguez Aramayo. Editorial Tecnos. Madrid, 1994.

- ¿ ¿Qué es la ilustración? En Filosofía de la Historia. Traducción y prólogo de Eugenio Imaz. Fondo de Cultura Económica. México, 1979.

- $\quad$ Sobre la paz perpetua. Trad. Y prólogo de Joaquín Abellán, presentación de Antonio Truyol y Serra. Editorial Tecnos. Madrid, 1998.

- $\quad$ La metafísica de las costumbres. Estudio preliminar y traducción de Adela Cortina y Jesús Conill, Ed. Tecnos, Madrid, 1989.

- $\quad$ En torno al tópico: "tal vez eso sea correcto en teoría, pero no sirve para la práctica". En Teoría y Práctica, Estudio preliminar y traducción de Juan Miguel Palacios García, M. Francisco Pérez López y Roberto Rodríguez Aramayo, Editorial Tecnos. Madrid, 2000.

- $\quad$ Crítica de la Razón Pura. Trad. Mario Caimi. Edit. Colihue. Buenos AiresArgentina, 2007.

\section{Otros}

Barceló, Joaquín (comp.). Selección de escritos políticos de Immanuel Kant (Introducción). Estudios Públicos, Número 34. 1989.

\footnotetext{
${ }^{27}$ Este punto no deja de ser anecdótico. En Chile, por ejemplo, la concentración del poder en pequeños grupos elitistas, tanto políticos como culturales, hacen un uso inmoral de legislaciones herederas de una dictadura; el impuesto a los libros (uno de los más altos del mundo), en tanto 'liberación de contenidos, y acceso de conocimientos y tomas de posturas a todos los ciudadanos', es un abuso que pretende nada más que entorpecer el proceso de ilustración de los más necesitados, una estrategia que la dictadura habría fomentado con objeto de evitar una Widerstand a su despotismo.
} 
Contreras Peláez, Francisco J.. El tribunal de la Razón; el pensamiento jurídico de Kant. Ed. Mad-Eduforma. Sevilla, 2005.

Cortina, Adela. Ética Mínima, introducción a la filosofía práctica. Tecnos. Madrid, 2000.

Hoyos, Luis Eduardo (Ed.). Estudios de Filosofía Política. Universidad Nacional de Colombia. Bogotá, 2004

Hoyos, L.E.; Patarroyo, C.; Serrano, G. Kant: entre sensibilidad y razón. Universidad Nacional de Colombia. Bogotá, 2006.

Lepe Carrión, Patricio. Religión natural y religión revelada: un indicio de Fichte en Kant". A PARTE REI. N056, Marzo 2008

Russo, Eduardo Ángel. Derechos Humanos y Garantías; El derecho al mañana. Eudeba (Editorial de la Universidad de Buenos Aires). Buenos Aires, 1999.

S/a. Convención Americana sobre Derechos Humanos suscrita en la Conferencia Especializada Interamericana sobre Derechos Humanos. San José, Costa Rica 7 al 22 de noviembre de 1969. En http://www.oas.org/juridico/spanish/tratados/b-32.html.

Ureña, Enrique. Kant, predecesor de Marx y de Freud. Tecnos, Madrid, 1979

Velasco Gómez, Ambrosio. La concepción republicana de kant. EPISTEME, jun. 2005, vol.25, no.2, p.109-122. 